\title{
REFLEXÕES ACERCA DO ASSISTENTE SOCIAL EM SUA DIMENSÃO EDUCATIVA COM FAMÍLIAS
}

\author{
Reflections on Social Worker in your educative dimension with families
}

\author{
Alana Andreia Pereira ${ }^{1}$ \\ Nayara Hakime Dutra de Oliveira ${ }^{2}$
}

\begin{abstract}
Resumo
As configurações familiares foram mudando ao longo do tempo de acordo com cada momento histórico, atendendo ao contexto das épocas, servindo a interesses hegemônicos para manobra social. Dentre as várias perspectivas do Serviço Social, este se apoia numa atuação a partir das expressões da questão social; nestas dimensões a face educativa aparece como uma das mais importantes e o profissional como educador social. Acerca disto, propõe-se a utilização da Educação Popular como norte para a exequibilidade deste trabalho com famílias, representantes familiares e grupos que reflitam sobre o convívio deste âmbito. Os desafios postos na contemporaneidade para esta reflexão são trabalhar as complexidades e vulnerabilidades familiares, respeitando os limites, possibilidades, divergências culturais, como também emancipação dos sujeitos.
\end{abstract}

Palavras-chave: Serviço Social. Família. Dimensão Educativa. Educação Popular.

\begin{abstract}
Familiar configurations were changing along the time according with each historical moment, attending to the periods' context, used by hegemonic interests for social maneuver. Among various perspectives of Social Service, this one relies on a performance from the expressions of social question; in this dimensions the educative side appears as one of the most importants and the professional as a social educator. Concerning this, propose the use of Popular Education as north to the practicability of this work with families, familiar representants and groups that reflect about living together of this spot. The challenges posed in contemporary to this reflection are work familiar complexities and vulnerabilities, respecting the limits, possibilities, cultural divergences, and subjects' emancipation.
\end{abstract}

Keywords: Social Worker.Family. Educative Dimension. Popular Education.

\footnotetext{
${ }^{1}$ Assistente Social, graduada pela UNESP Franca, Especialista em DST/HIV/AIDS, Serviço Social e Saúde pela FCM UNICAMP.

2 Professora Doutora do Departamento de Serviço Social da UNESP de Franca.

Serv. Soc. \& Saúde, Campinas, SP v. 12, n 1 (15), p. 65-82 jan./jun. 2013 ISSN 1676-6806
} 


\section{INTRODUZINDO O DEBATE}

A trajetória da família desde sua gênese até a contemporaneidade demonstra seu caráter de lócus construtor de personalidade, primeiro exemplo de sociabilidade e responsável pela inserção de novos membros ao convívio em comunidade. Para a compreensão da pertinência de todo este processo, aprioristicamente discorreu-se sobre a história da família, suas relações e a atual centralidade da mesma nas políticas públicas brasileiras. Posteriormente, foi feita uma contextualização da cena brasileira, buscando explicitar fatos que persistem ainda hoje interferindo na conjuntura social, como também foram analisadas as políticas públicas, seu caráter e suas propostas.

Buscou-se conhecer também a Educação Popular como proposta de utilização por esta alternativa para atuação do Serviço Social em sua dimensão educativa, por acreditar que este meio de intervenção pode proporcionar resultados importantes quando no trato com sujeitos em vulnerabilidade social, baixa escolaridade, ou aqueles que necessitam de outros meios para exercer sua cidadania enquanto sujeitos munidos de direitos. Por fim, procurou-se refletir e discutir quanto à Educação Popular como proposta interessante para o Assistente Social no trato de sua potencialidade educativa.

\section{FAMÍLIA E SUAS RELAÇÕES}

A família e suas relações é um tema de constante discussão, sendo necessário perpassar por uma breve contextualização das perspectivas aqui defendidas, no que tange à conjuntura familiar, que se dá com a finalidade de articular a sociabilidade entre as antigas organizações, tribos, ou ainda as chamadas "gens". Ao longo do tempo apareceram diversas configurações familiares que foram sofrendo modificações de acordo com o espírito da época expressado pela cultura popular que impõe papéis sociais, atendendo a interesses hegemônicos com o escopo de controlar socialmente a população.

Uma das mais importantes desmistificações da origem da família foi a de Friedrich Engels, pela gama de concepções acerca do tema por ele levantadas. O autor perpassa pela gênese da família, até a tradicional monogamia, sendo esta a configuração mais aceita até a atualidade, tendo por diretriz a supremacia do homem sobre a mulher, e a família individual como unidade econômica da sociedade (ENGELS, 2010, p. 221)

Não obstante, partindo da perspectiva de Lévi-Strauss, ocorre um evolucionismo a partir da era da civilização que considera esses povos antigos como "bárbaros”, pois 
afirma que os mesmos não possuíam grau de socialização, sendo assim, povos aculturais, portanto, sem valores e conceitos de vida necessários a terem consciência.

[...] a família baseada no casamento monogâmico era considerada instituição digna de louvor e carinho, inferiu-se imediatamente que as sociedades selvagens - equiparadas para os fins em vista às existentes no início da humanidade - somente poderiam possuir algo diferente. Como consequência, os fatos foram torcidos e mal interpretados; ainda mais, inventaram-se fantasiosos estádios "primitivos" de evolução, tais como "casamento em grupo" e "promiscuidade", para justificar o período no qual o homem era ainda tão bárbaro que não poderia conceber os primores da vida social cujo gozo constitui privilégio do homem civilizado. Cada costume diferente dos nossos era cuidadosamente selecionado como vestígio de um tipo mais antigo de organização social (LÉVI-STRAUSS, 1956, p.308).

Analogamente a estas acepções, o que não se pode negar é que a origem da sociabilidade surge com a família, de modo consciente ou inconsciente, destarte, foram sendo necessárias organizações, regras, direitos, costumes e deveres para o convívio em grupo, chegando à civilização.

Uma característica que deve ser elucidada desta ordem social é a banalização do comum e o fato de todos evitarem relações em qualquer nível para evitar as complicações implícitas nesses convívios próximos, sendo evidenciado como sentimento principal e gerador de organizações sociais ao longo da história temos o amor, que é brilhantemente tematizado por Del Priore (2006, p. 319) ao dizer que :

\begin{abstract}
A sexualidade e o amor têm cronologias próprias, cronologias que escapam, aparentemente, aos fatos políticos e econômicos. Impossível contar sua história à luz dos temas que habitualmente preenchem os livros sobre história do Brasil. Dentro, contudo, das transformações pelas quais passou a sociedade brasileira poderíamos expor o seguinte: o que se assistiu no decorrer do tempo foi uma longa evolução que levou da proibição do prazer ao direito ao prazer.[...]
\end{abstract}

Há alguns séculos se passou a venerar a união mística entre amantes, romanticamente exaltada por trovadores medievais, o que tornou popular o amor romântico. Por conseguinte, atualmente em relacionamentos duradouros, sentimentos como amor e afeto são considerados primordiais. Perante o exposto, a família passa a ser cada vez mais pressionada para corresponder a esta moral, esquecendo-se que cada âmbito familiar tem suas particularidades, problemas a enfrentar, bem como, o fato de não existir apenas uma maneira de amar e sim, inúmeras, pois cada sujeito possui 
características que o difere dos demais, acarretando amores distintos, sendo cada um tão importante e verdadeiro quanto o outro.

Esses são fatos observáveis em todo contexto histórico social, como a delimitação da propriedade privada como meio de apropriação de riqueza e a família como instituição, responsável por inserir o indivíduo na sociedade já iniciado em um meio social. Analogamente a esta ideia é importante reforçar a partir do ponto de vista de Lévi-Strauss (1956, p. 332) ao colocar que, “A sociedade pertence ao reino da cultura, enquanto a família é a origem, no nível social, daqueles requisitos naturais sem os quais não poderia haver sociedade nem, certamente, humanidade.”

Esta conduta muitas vezes pode gerar determinados conflitos nestes espaços familiares, fazendo com que muitos sejam oprimidos e tomem posturas distintas para se adequarem e evitarem atritos.

Neste contexto, a partir da instituição de controladores sociais por parte de alguns estamentos surge então, por meio da "fé” e superstição, a religião, sendo como ápice da religiosidade a doutrinação e o domínio por parte do catolicismo.

Como bem interpreta Chauí acerca da filosofia de Espinosa,

[...] a imaginação nos leva a forjar, a imagem de um ser supremo, onipotente e onisciente, que tudo governaria seguindo os caprichos de sua vontade e segundo fins incompreensíveis para os humanos: Deus. Para conseguir benefícios, afastar malefícios, obter a boa vontade e aplacar a cólera desse ser supremo, a imaginação dá mais um passo, inventando a religião como conjunto de cultos à divindade (CHAUÍ,1995, p. 34).

O catolicismo inicia uma era de difusão de sua doutrina, defendendo a monogamia, fazendo com que qualquer outra orientação sexual fosse vista como uma anomalia. A partir daí esta união passa a ser indissolúvel, o sexo é colocado como prática voltada para a reprodução, ou ainda, pode-se dizer que a essência do sacramento do matrimônio é o ato conjugal, e se a relação sexual se der fora deste, é considerada uma atitude de desobediência, ou seja, pecado.

Com a entrada no século XX a relação de proximidade entre Estado e Igreja começou a se desgastar e, surge o casamento civil, fazendocom que a religião deixe de ser o ápice da hierarquia social e novas configurações familiares foram passando a existir, tomando como marco para tanto, a entrada da mulher no mercado de trabalho.

A Revolução Industrial foi um marco junto ao ganho de espaço do movimento social de mulheres aderindo ao mercado de trabalho. Todo este novo cenário acarretou 
para o contexto familiar novas perspectivas. A partir desta nova realidade da mulher, a mesma passou pelo comprometimento de sua estabilidade emocional, profissional e social, já que, passaram por inúmeras discriminações por conta do machismo intrínseco às sociedades capitalistas modernas, bem como pelas discriminações sofridas em seu período de maternidade, como por seu estado civil, tendo como consequência punições e intolerância por suas condições específicas divergentes as do sexo masculino, fatos estes que ainda hoje exalam resquícios.

Acerca disso, podemos inferir junto à Virgínia Paes Coelho (2002) que a partir do momento em que as mulheres passam a ser chefes de família, preocupando-se com o perfil do mercado de trabalho por ser este excludente, induzindo os profissionais à especialização e sucateando cada vez mais a mão de obra, faz com que elas busquem por investir em suas profissões por conta também da competitividade. Ademais, é preciso citar a questão da baixa remuneração por conta da discriminação e opressão das mulheres no mercado de trabalho - gerando a necessidade delas ocuparem mais de uma vaga por serem elas as mantenedoras familiares -, não obstante, o interesse por ter filhos e por relações duradouras em sua maioria foram mantidos.

Sobre as configurações familiares existentes é interessante salientar que segundo o Instituto Brasileiro de Geografia e Estatística (IBGE), na atualidade são: a unipessoal, composta por apenas uma pessoa; casal com filhos, casal sem filhos e mulheres sem cônjuge com filhos. De acordo com Gislene Neder,

Parte-se, portanto, da ideia de que não existe, histórica e antropologicamente falando, um modelo padrão de organização familiar; não existe a família regular. Menos ainda que o padrão europeu de família patriarcal, do qual deriva a família nuclear burguesa (que a moral vitoriana da sociedade inglesa no século XIX atualizou historicamente para os tempos modernos), seja a única possibilidade histórica de organização familiar a orientar a vida cotidiana no caminho do progresso e da modernidade. Pensar as famílias de forma plural pode significar uma construção democrática baseada na tolerância com as diferenças, com o outro (NEDER, 1994, p.28).

É importante também evidenciar que a família, no contexto regido pelo sistema capitalista, tem uma função produtiva, sendo o âmbito que deve proporcionar o bem estar para o trabalhador com o interesse de que o mesmo esteja sempre a postos para 
exercer seu trabalho. Para tanto, em geral é a mulher que deve se ocupar dos serviços domésticos, trabalho esse não pago, sendo a maior exploração da sociedade capitalista.

Rebuscando ainda alguns percalços históricos como a industrialização e urbanização, podemos apontar como avanços que quebraram as amarras sociais, o fato da saída da mulher dos afazeres domésticos para o mercado de trabalho, gerando novas configurações familiares que vem tentando ganhar espaço e aceite; também temos o controle de natalidade e a melhoria na área da saúde e nas políticas públicas. Como retrocessos temos o segregacionismo nas relações, culminando da exacerbação do individualismo.

Na atual conjuntura há uma busca incansável pela felicidade, fazendo com que esta deixe de ser a resultante das ocorrências para que seja a iniciativa. Geralmente esta ânsia tem sido saciada através do consumo material, com isso o final feliz para sempre, vem substituir a salvação pela religião, proporcionando através do imaginário uma realização encontrada na felicidade privada, ou seja, no individualismo.

O vínculo familiar deve ser formador de personalidade, senso crítico e deve incitar trocas de conhecimento entre seus membros, não obstante, a segregação desta instituição é cada vez mais um motivo de preocupação. A desvalorização deste âmbito é em grande parte, expressão do universo capitalista marcado pela exploração, desigualdade, fragmentação e competitividade, que relega à família a função econômica de socialização de recursos entre seus membros.

\section{A CENTRALIDADE DA FAMÍLIA NAS POLÍTICAS PÚBLICAS}

O Estado brasileiro propõe a centralidade da família nas políticas públicas, bem como a emancipação dos sujeitos, não obstante, o contexto aparece a cada momento com maior contraditoriedade, no qual as intervenções e manifestações dos direitos continuam sendo minimalistas, assistencialista e, portanto, clientelistas, isto se deve às assimetrias geradas pela incorporação das doutrinas neoliberais que em suas diretrizes dispõe sobre a intervenção mínima Estatal.

Este clima de desresponsabilização por parte do Estado dá margem às privatizações, as Organizações não governamentais, que são organizações de pessoa jurídica do direito privado e de interesse público, portanto, organizações privadas, que recebem benefícios como imunidade tributária e recursos públicos. 
O contexto de centralização da gestão pública, que diz prezar pela descentralização faz justamente o oposto, quando propõe políticas públicas reducionistas, clientelistas, que atingem apenas um pequeno contingente da população, visto que, a maioria das propostas legislativas deságua em práticas caritativas e filantrópicas que continuam ocorrendo, como foi dito acima, na maioria dos casos utilizando de recursos federais, estatais e municipais. A despeito disto Oliveira e José Filho (2009, p.59) afirmam que:

[...] o que está presente e com força total na atualidade é o Welfare Mix, combinando recursos e meios mobilizáveis do Estado, do mercado, das Organizações não governamentais (ONGs), das organizações sociais sem fins lucrativos e da rede de solidariedade existente nas famílias, nas Igrejas, na própria população local. As políticas sociais se apresentam com as responsabilidades partilhadas.

O ideário neoliberal em suas propostas admite que as assimetrias do sistema são corrigidas a partir do respeito à determinada ordem econômica que perpetue a autoregulação de mercado, sendo assim, estas diretivas passam a ser tomadas como leis, regras inquestionáveis, entretanto, este cenário pode e deve ser averiguado, sendo dever do cidadão não se submeter à estagnação, embora, não possamos exigir das pessoas tal conduta, tal ideário nos conduz a isso, nos segrega, desarticula, querendo determinar nosso destino, pois sendo pobre ou rico, o cidadão pode saber que é explorado e não aprovar o neoliberalismo, mas sabe que sozinho não tem como impedi-lo.

O grande poder místico desta ordem sobre a população de maneira geral é explícito, uma vez que, este sistema é tão perverso que é capaz de expropriar uma determinada classe, sugando os trabalhadores, alienando-os, deixando-os sem tempo para pensar, sem perspectiva de vida e, destarte, impedindo revoltas, tudo isto gera a rotina, o fatalismo e o conformismo.

O Brasil carece de produção própria de ideias e de priorizar a nossa história, pois adota doutrinas internacionais para sanar inúmeras lacunas, aderindo às receitas prontas que nem sempre levam em consideração as particularidades de cada país. Esquecemos que tais conceitos externos foram resultados de outras vivências e adormecemos em um estranhamento de realidades.

Este estranhamento é resultado de toda uma gama de contradições no cenário público que acabam afetando a vida de cada cidadão por interferir diretamente no Serv. Soc. \& Saúde, Campinas, SP v. 12, n 1 (15), p. 65-82 jan./jun. 2013 ISSN 1676-6806 
mercado de trabalho, promovendo estudos voltados para a prática e não para a teoria, segmentando os meios de produção, o que ocorre a partir do embate entre capital versus trabalho aumentando o grau de alienação do funcionário, fazendo com que o mesmo não se reconheça em suas ações, gerando a tecnificação, segundo os dizeres de Marx acerca do estranhamento, no capítulo “Trabalho Estranhado” em Manuscritos Econômico Filosóficos.

No Brasil o capitalismo instaura-se tardiamente, sendo este fator determinante para a total falta de nivelamento na distribuição de renda e da propriedade privada, sob uma política de privilégios para poucos e privações para muitos.

Procurando rebuscar a historicidade política brasileira, faz-se necessário uma análise de conjuntura sob a perspectiva da totalidade da realidade brasileira, que será discutido na sequência.

O neoliberalismo surge então como alternativa e retomada do liberalismo, sendo assim, contrário ao Welfare State (“Estado de Bem Estar Social”), ou ainda o Estado enquanto controlador social, esta reabertura à esta vertente ganha espaço com a crise no mundo capitalista de 1929. Dentro desta nova agenda o Estado deve intervir minimamente na economia, visto que, a interferência corrompe a liberdade individual livre arbítrio, jusnaturalismo -, como também o curso "natural” do mercado, que deve se auto regular (BEHRING, 2008).

Dentro deste sistema capitalista a classe operária - por operária entende-se como a classe que vive do trabalho - surge como expropriada e super explorada, por inúmeros fatores como a terceirização e a segmentação nas funções da produtividade, o que resulta na precarização do trabalhador que é alienado a partir da extração da mais-valia (MARX, 1987, v.1), que nada mais é que o trabalhado excedente, ou seja, o trabalho não pago pelo empregador, que é chamado pelo empregador de lucro.

Com isso, o Estado apesar de toda sua característica tangente e intangível, acaba por necessitar voltar seu olhar para as mazelas sociais e com a intenção de conter os revoltosos utiliza-se de políticas públicas, verticalistas, ou ainda, sem buscar entender a realidade para que a partir da mesma possa obter respostas e alternativas com veracidade nos fatos.

Ademais, essa atitude priva o sujeito de sua cidadania política e social, desconsiderando dados regionais e necessidades básicas elencadas pelo próprio interessado, determinando ao Brasil o caráter de democracia restrita. Essa hegemonia visa apenas à contenção das expressões da questão social, conforme a aparição dos Serv. Soc. \& Saúde, Campinas, SP v. 12, n 1 (15), p. 65-82 jan.jun. 2013 ISSN 1676-6806 
fenômenos, deixando de lado a real prioridade, que deveria ser a de desvelar o real, ultrapassando a pseudoconcreticidade a partir da atenção às particularidades do universo singular alvo destas políticas.

O Estado, por sua vez, estabelece que a família e a comunidade são os primeiros responsáveis pelo sustento de seus entes, sejam eles idosos, crianças ou ainda os considerados incapazes, cabendo ao setor público intervir apenas quando constatada a vulnerabilidade social. Desse modo, a prevenção fica a desejar e a intervenção também, já que esse estágio de vulnerabilidade ainda não é algo bem definido nas políticas sociais.

Não obstante, a partir de 1988 com a Constituição Federal a Assistência Social passa a fazer parte do tripé da Seguridade Social, junto à Previdência Social e a Saúde, nela a proteção à família aparece como principal objetivo, criando, destarte, um ambiente contraditório, no qual o Estado ao passo que se exime também propõe a atenção especial à família.

Em 1993, surge a Lei Orgânica de Assistência Social (LOAS) que busca enfatizar e transformar em ações o que já havia sido previsto na Constituição Federal de 1988.

A Política Nacional de Assistência Social (PNAS) de 2004, sendo grande conquista para os cidadãos e movimentos sociais trás em sua $5^{\text {a }}$ diretriz a "centralidade na família para concepção e implementação dos benefícios, serviços, programas e projetos” (BRASIL, 2004, p. 27).

Ademais, retomando a LOAS é importante evidenciar aqui o princípio da centralidade da família que compete ao artigo $2^{\circ}$ desta lei:

Art. $2^{\circ}$ A assistência social tem por objetivos:

I - a proteção à família, à maternidade, à infância, à adolescência e à velhice;

II - o amparo às crianças e adolescentes carentes;

III - a promoção da integração ao mercado de trabalho;

IV - a habilitação e reabilitação das pessoas portadoras de deficiência e a promoção de sua integração à vida comunitária;

V - a garantia de 1 (um) salário mínimo de benefício mensal à pessoa portadora de deficiência e ao idoso que comprovem não possuir meios de prover a própria manutenção ou de tê-la provida por sua família (BRASIL. Lei n ${ }^{\circ} 8742$ de 7 de Dezembro de 1993). 
Vale ressaltar a respeito do acima exposto que a nebulosidade e inocuidade das legislações ficam evidentes quando se trata das necessidades básicas das famílias, uma vez que, os programas de transferência de renda geram o clientelismo, quando não prezam pela emancipação e autonomia, bem como quando enfatizam a mulher como a organizadora da casa, aquela que deve cuidar da família, fato esse que desresponsabiliza o Estado e seu companheiro (a), além de atrelá-la mais uma vez aos afazeres domésticos. Dentro disso, surgem as propostas de trabalhos socioeducativos para acompanhar estes direitos sociais, em contrapartida os serviços públicos encontram-se cada vez mais sucateados, sendo assim, é difícil afirmar que a reflexão crítica necessária é realmente atingida a partir desses grupos.

A Política Nacional de Assistência Social (PNAS) de 2004 vem explicitar ainda, como prioridade para uma análise de conjuntura que a mesma deve ser pautada por um olhar para o território em que os sujeitos vivem, para que seja possível atingir realmente as necessidades dos mesmos.

Tendo a família como foco a partir do princípio da matricialidade, sendo entendida não somente como um núcleo formado por membros consanguíneos, mas considerando o âmbito institucional, de convívio, trocas plurais, que necessita de apoio para sua sustentabilidade, dando condições para que estas relações se concretizem e a operacionalização da implementação das políticas surge a Norma Operacional Básica de Assistência Social (NOB/SUAS).

Aliás, atualmente para as políticas ”[...] estamos diante de uma família quando encontramos um conjunto de pessoas que se encontram unidas por laços consanguíneos, afetivos e, ou de solidariedade” (BRASIL, 2004, p. 35).

Por consequência, as concepções acerca da família sofreram modificações e a visão da necessidade do Poder Público Estatal também, mesmo com o caráter neoliberal vigorando, entretanto, isto tende a dificultar cada vez mais a efetividade das políticas públicas que visem atender aos sujeitos em totalidade, pois a ótica de intervenções mínimas provoca a segregação e a focalização nos indivíduos. Como assinala Oliveira e José Filho,

Auferir para as famílias a divisão de responsabilidades sem dar às mesmas as mínimas condições de suportar o fardo de ser corresponsável por sua subsistência é mais uma transferência de responsabilidades do que uma divisão, pois quando há algo para se dividir, ambos ficam com certa parte. No que diz respeito à família como centralidade nas políticas sociais, o que podemos verificar é que 
a família ficou com a parte pior: a de sobreviver sem os mínimos meios para atingi-la (OLIVEIRA, 2009, p. 62).

\section{A EDUCAÇÃO POPULAR COMO NORTE}

O Serviço Social busca constantemente por meios para atingir sua intencionalidade junto aos sujeitos partícipes principais de sua atuação. Por conta disso, trabalhar toda esta gama de questões presentes no universo familiar exige do profissional discernimento de alguns conceitos e argumentações com relação a utilização da Educação Popular para este fim.

Primeiramente, concebemos que a educação não se restringe ao âmbito formal escolas -, pois ela ocorre nos mais diversos espaços e situações inusitadas, cabendo ao Assistente Social em sua dimensão educativa participar desta ideia e contribuir com o que lhe cabe, no que tange às dúvidas e informações que competem ao Serviço Social e que são necessárias aos sujeitos atendidos pelo mesmo. Analogamente ao acima exposto, é possível completar com Mészáros (2008) quando diz que,

Considerando esse mais amplo e mais profundo significado da educação, que inclui de forma proeminente todos os momentos de nossa vida ativa, [...] é decida, para o bem e para o mal - não apenas para nós próprios como indivíduos, mas simultaneamente também para a humanidade -, em todas aquelas inevitáveis horas que não podemos passar "sem aprender". Isso porque "a aprendizagem é, verdadeiramente, a nossa própria vida” (ibid., p. 48).

A educação popular se dá não apenas em ambientes institucionais, o que consiste em seu diferencial, pode ocorrer em Movimentos Sociais, associações de moradores, grupos de diversos tipos e interesses.

A respeito da Educação Popular existem diversos tipos de concepções, entretanto, valoriza-se aqui a ótica de Paulo Freire, a qual a libertação é a diretriz, ou ainda segundo Wanderley (2010) é a procura por fortalecer as potencialidades do povo, a valoração da cultura popular, a busca pela auto conscientização, capacitação, participação, podendo tudo isso ser concretizado a partir da troca de saberes entre 
agentes e membros das classes populares, realizando reformas estruturais na ordem do capital (WANDERLEY, 2010). Neste sentido, segundo Paulo Freire,

[...] a pedagogia do oprimido, como pedagogia humanista e libertadora, terá, pois, dois momentos distintos ainda que relacionados. O primeiro, no qual os oprimidos vão desvelando o mundo da opressão e vão se comprometendo, na práxis, com sua transformação, e, o segundo, no qual uma vez transformada a realidade opressora, essa pedagogia deixa de ser do oprimido e passa a ser a pedagogia dos homens no processo de permanente libertação (FREIRE apud WANDERLEY, 2010, p. 22).

A Educação Popular é uma educação ligada essencialmente a classe trabalhadora, portanto popular, visto que, exige consciência, é histórica, já que depende do avanço das massas produtivas; política, por aliar-se a uma determinada camada, sendo esta a popular; transformadora e libertadora, por dar subsídios ao conhecimento, amadurecimento e autoconscientização, bem como a luta por reformas estruturais, não sendo reformistas, ou ainda, não fazer pequenas alterações sem mexer na estrutura; é democrática, sendo assim, contra a arbitrariedade, antimassificadora, antielitista; a favor da práxis, por relacionar teoria e prática constantemente; a busca por utilizar o trabalho e as vivências dos sujeitos como meios para explicações educativas e, tudo isto objetivando a efetivação do poder popular (WANDERLEY, 2010). Existem três inclinações da Educação Popular, são elas:

1) a educação popular é, em si mesma, um movimento de trabalho pedagógico que se dirige ao povo como um instrumento de conscientização etc.; 2) a educação popular realiza-se como um trabalho pedagógico de convergência entre educadores e movimentos populares, detendo estes últimos a razão da prática e, os primeiros, uma prática de serviço, sem sentido em si mesma; 3) a educação popular é aquela que o próprio povo realiza, quando pensa o seu trabalho político - em qualquer nível ou modo em que ele seja realizado, de um grupo de mulheres a uma frente armada de luta - e constrói o seu próprio conhecimento (BRANDÃO apud WANDERLEY, 2010, p. 23).

Consideramos, ademais, que a Educação Popular aparece como um meio de alcance da sonhada consciência de classe, sendo este o caminho para uma nova ordem social e, portanto, um instrumento contra hegemônico; por isso, a utilização desse deve ser perpetuada, não apenas em escolas, grupos, atendimentos institucionais e de comunidades, como também, atendimentos específicos (WANDERLEY, 2010).

Retomando as ideias anteriormente colocadas com relação à atual cena social, é preciso elucidar que este ambiente de fragmentação das relações e competitividade tem Serv. Soc. \& Saúde, Campinas, SP v. 12, n 1 (15), p. 65-82 jan./jun. 2013 ISSN 1676-6806 
sido perpetuado pelo neoliberalismo e, como resultante tem afetado os movimentos sociais, sindicais e todos os tipos de organizações populares, corrompendo-os e segmentando-os, o que torna, cada vez mais raras, as comoções e uniões de pessoas na luta por determinada causa.

Destarte, é uma política de desarticulação das massas, dominando pela moral hegemônica, tecnologia e consumismo, desresponsabilizada de futuras repercussões de sua exploração e utilização, através da proposta de globalização autoritária, desmedida, pela economia neoliberal.

A congruência entre a elevação do privado em detrimento do comum e o fetichismo material eleito como melhor maneira para a sensação de felicidade por meio da manipulação, vem evidenciar o quão imerso nessa moral e modo de produção hegemônica o ser humano está, pois, este sistema necessita que todos estejam consumindo, mesmo que minimamente, estimulando assim a circulação de mercado.

Esta lógica de mercado permite ao indivíduo um sentimento de inclusão nesta ordem societal, pelo acesso a tecnologias mesmo que de forma restrita e à custa de muito trabalho, enquanto isso, a percepção da realidade torna-se algo visível, mas indesejado, devido ao profundo estado de conformismo e alienação da população. Na contemporaneidade, a conquista de uma democracia plena pressupõe o rompimento com tais valores hegemônicos.

A Educação Popular, desse modo, é um meio interessante para que todos os sujeitos possam ser alcançados, ressaltando sempre que estes são sujeitos históricos e como tal, devem ser compreendidos em seu universo singular, respeitando suas particularidades, buscando sempre ultrapassar a pseudoconcreticidade, ou ainda, a camada dos fenômenos, para que, destarte, seja possível uma construção, uma troca plural, consciente entre o profissional do Serviço Social e os sujeitos objetivados.

A título de esclarecimento, vale ressaltar, no que tange à pseudoconcreticidade, que se trata de um processo de ultrapassar o imediatismo concreto, ou ainda, ideias, “achismos” e posturas tomadas a partir do aparente, passando pela abstração, cuja circunstância deve ser analisada e selecionada a priori pelo todo, possibilitando a chegada pelas partes ao real, ou seja, a essência do fenômeno. Ou, de acordo com Kosik (1976, p. 30), 
[...] da vital, caótica, imediata representação do todo, o pensamento chega aos conceitos, às abstratas determinações conceituais, mediante cuja formação se opera o retorno ao ponto de partida; desta vez, porém, não mais como ao vivo mas incompreendido todo da percepção imediata, mas ao conceito do todo ricamente articulado e compreendido.

É válido ressaltar que a Educação Popular privilegia a cultura presente nos espaços educativos. Nesse sentido, pode-se inferir com Wanderley que:

Bosi (1994) entendia cultura como "uma herança de valores e objetos compartilhada por um grupo humano relativamente coeso”, e indicava uma tipologia assim demarcada: cultura erudita, centralizada no sistema educacional e predominantemente nas universidades; cultura popular, correspondendo aos mores materiais e simbólicos do homem sertanejo e interiorano, e do homem pobre suburbano; cultura de massas, também conhecida como indústria cultural, cultura de consumo; cultura criadora individualizada de escritores, compositores, artistas clássicos, cineastas, dramaturgos etc (BOSI apud WANDERLEY, 2010, p. 30-31).

A cultura popular, portanto, não deve ser colocada como algo inferior, pelo contrário, ela mantém o apreço pelo comum, pelo histórico de determinado povo, seus costumes, valores, que são determinantes na constituição da personalidade do ser humano e de seus papéis sociais - um sujeito pode vir a ter diversos ocupações sociais ao mesmo tempo, sendo dentre os possíveis o de pai, de mãe, o de trabalhador(a), amigo(a), filho(a), idoso (a).

Acerca disto, a cultura popular compõe fatores fundamentais para a Educação Popular, pois a mesma se consubstancia nas vivências dos sujeitos e, é a partir dela, a cultura popular, que se torna possível compreender as reais influências, interesses e especificidades dos sujeitos, para serem, em conjunto, compartilhados e refletidos.

Em face ao exposto, torna-se possível neste momento a reflexão acerca do trabalho do Assistente Social em sua dimensão educativa, por ser esta um importante instrumental a ser explorado pela categoria, o que este estudo vem propor é a utilização da Educação Popular como alternativa para a efetivação da visão transformadora do Serviço Social prevista pelo Projeto Ético Político da classe.

O Serviço Social é uma profissão inserida na divisão sociotécnica do trabalho, portanto, é uma categoria que compõe a classe trabalhadora assalariada, que a partir do movimento de reconceituação - o qual expressa o processo de tomada de consciência de classe, se posicionaram hegemonicamente contra a supremacia de poucos em 
detrimento de muitos, embora esta postura heterogênea o Projeto Ético Político vem elucidar esse posicionamento tornando válido e categórico este posicionamento político.

Os preceitos da Educação Popular, por conseguinte, podem contribuir em muito para a exequibilidade da atuação dos Assistentes Sociais em sua práxis profissional, como na questão do processo de tomada de consciência de classe dos sujeitos, fomentando o senso crítico e político, para que possam refletir e tentar modificar suas próprias realidades, buscando alternativas e questionando, pois aquele que para de questionar ou que nunca questiona torna-se estagnado, conformado.

\section{CONSIDERAÇÕES FINAIS}

No decorrer da procura pelo entendimento das questões presentes no espaço do trabalho com famílias, suas configurações, modificações e funções sociais, foi possível compreender que estas relações, no Brasil, vão sofrendo alterações de acordo com a conjuntura da época, de acordo com o contexto histórico, as influências da moral e doutrina econômica vigentes.

As políticas públicas em suas preconizações propõem a centralidade da família, embora sejam contraditórias pela influência neoliberal de políticas minimalistas e clientelistas. Tais políticas acabam por super responsabilizar a família invés de socializar a educação de seus membros, socializar o trabalho doméstico, possibilitando a reflexão e o rompimento com a opressão pela qual a mulher é tomada em nossa sociedade machista e classista.

Ao evidenciarem-se os usos que fazemos do contexto familiar, pode-se dizer que se espera que seja em sua aplicabilidade social um ambiente de construção, de afetividade, troca de saberes, estimulando a reflexão e a criticidade, mas devemos conceber que ele pode não o ser. Portanto, não devem existir padrões, nem se deve exigir que esta instituição dure para sempre ou mesmo que tenha prazo de validade, mas os padrões existentes precisam ser desconstruídos.

Face ao exposto, a dimensão educativa no trabalho do Assistente Social já se utilizou de diversos ideários como o moralista, o psicologizante, o meramente informativo e o socioeducativo. Porém este estudo buscou evidenciar que a Educação Serv. Soc. \& Saúde, Campinas, SP v. 12, n 1 (15), p. 65-82 jan./jun. 2013 ISSN 1676-6806 
Popular é um interessante recurso a ser utilizado, que atende aos princípios profissionais desta categoria, pois tem como norte contribuir para com a emancipação social.

Dentro desta ideia, ademais, o Assistente Social tendo por competência profissional o trabalho com grupos e sujeitos, pode proporcionar espaços de trocas reflexivas, críticas, descontraídas através de meios lúdicos, instigando os sujeitos ao debate de aspectos levantados por eles mesmos.

No campo das intervenções do Serviço Social diretamente com os sujeitos é preciso pensar em como contribuir para com o processo de tomada de consciência de classe, buscando constituir uma ação contra hegemônica no uso de suas competências teórico-metodológica, técnico-operativa e ético-política, respaldado em suas dimensões investigativa, interventiva, educativa e ético-política, bem como em seu Código de Ética Profissional e Projeto Ético Político. A categoria profissional deve ainda, via de regra, hastear a bandeira da luta por políticas públicas coesas, que atendam à cena societal, tomando por diretrizes a perspectiva de totalidade, a universalização e a descentralização.

\section{REFERÊNCIAS}

BEHRING, E. R. Política social: fundamentos e história. São Paulo: Cortez, 2008. BRASIL. Política Nacional de Assistência Social (PNAS). Diário Oficial da União. Poder Legislativo. Brasília, DF, 15 out. 2004 Disponível em: <http://www.mds.gov.br>. Acessado em: 25 jul. 2011.

BRASIL. Constituição da República Federativa do Brasil.1988. Diário Oficial da União. Poder Legislativo. Brasília, DF, 05 out. 1988. Disponível em: <http://www.ovp-sp.org/lei_art5consttic.htm>. Acesso em: 25 jul. 2011. BRASIL. Lei nº 8.069, de 13 de julho de 1990. Dispõe sobre o Estatuto da Criança e do Adolescente e dá outras providências. Diário Oficial da União. Poder Legislativo. Brasília, DF, 16 jul. 1990. Disponível em: <http://www.planalto.gov.br/ccivil_03/Leis/L8069.htm>. Acesso em: 26 ago. 2011. BRASIL. Lei Orgânica da Assistência Social (LOAS), Lei no 8724/1993 de 07 de dezembro de 1993. Diário Oficial da União. Poder Legislativo, Brasília, DF, 07 dez. 1993. Disponível em: < http://www.assistenciasocial.al.gov.br/legislacao/legislacaofederal/LOAS.pdf/view>. Acessado em: 29 jul. 2011.

CHAUÍ, M. de S. Espinosa: uma filosofia de liberdade. São Paulo: Moderna; 1995. Serv. Soc. \& Saúde, Campinas, SP v. 12, n 1 (15), p. 65-82 jan./jun. 2013 ISSN 1676-6806 
COELHO, V. P. O trabalho da Mulher, Relações Familiares e Qualidade de Vida.

Serviço Social \& Sociedade. São Paulo, ano 23, n. 71, p. 63 - 79 , 2002.

DEL PRIORE, M. História do amor no Brasil. São Paulo: Contexto, 2006.

ENGELS, F. A origem da família, da propriedade privada e do Estado. 10ª Ed., Rio de Janeiro: Civilização Brasileira, 2010.

KOSIK, K. Dialética do concreto. Rio de Janeiro, Paz e Terra, 1976.

LÉVI-STRAUSS, C. A família. In: SHAPIRO, H. L. Homem, cultura e sociedade.

São Paulo: Fundo de Cultura, 1956.

MARX, K. O capital: crítica da economia política. São Paulo: Bertrand Brasil, vol. 1, 1987.

MÉSZÁROS, I. A Educação para além do capital. [tradução Isa Tavares]. 2.ed. São Paulo: Boitempo, 2008.

OLIVEIRA, N. H. D., JOSÉ FILHO, M. O trabalho Social com famílias: repercussões, possibilidades e desafios. Serviço Social \& Realidade, Franca, v. 18, n. 2, p. 55 - 80, 2009. 
